\title{
A narrativa-contra de Chove nos campos de Cachoeira, de Dalcídio Jurandir
}

\author{
The counter-narrative of Chove nos campos de Cachoeira, by Dalcídio Jurandir
}

\author{
Pedro Barbosa Rudge Furtado ${ }^{1}$ \\ Universidade Estadual Paulista “Júlio de Mesquita Filho", Araraquara, SP, Brasil.
}

\begin{abstract}
A Pará.grafo editora tomou a iniciativa de relançar, por meio de financiamento coletivo, parte da obra de Dalcídio Jurandir ${ }^{2}$, talvez o mais conhecido romancista da Amazônia. No que se refere à nova publicação de Chove nos campos de Cachoeira - romance aqui resenhado - a última edição contrapõe-se à anterior organizada por Rosa Assis, lançada pela editora 7 Letras, em 2011. A tiragem de 2011 dedicou-se, por meio de diversas investigações do acervo do autor na Fundação Casa de Rui Barbosa, a preparar o texto a partir de escritos nos quais o literato alterou trechos significativos da prosa. A Pará.grafo, no entanto, retoma o arranjo do primeiro lançamento do romance, realizado pela Vecchi Editora em 1940, a fim de reparar "a 'desobediência' à exigência equivocada da sétima edição [da 7Letras], que alterou o texto original e se pretendeu definitiva [...]" (PANTOJA, 2019, p. 18).
\end{abstract}

A despeito desse importante debate editorial, é relevante realçar que a importância da republicação de alguns livros do "Ciclo do Extremo-Norte" encontra-se na maior difusão de um escritor de leitura imprescindível da nossa literatura, tanto em termos do direcionamento do leitor/crítico para uma área pouco explorada pelo centro econômico brasileiro, quanto por um cuidado estético raramente consagrado nos efervescentes decênios de 1930 e 1940.

Marlí Tereza Furtado (2015, p. 204), uma das principais estudiosas da obra dalcidiana, conjuga diversos elementos a fim de incluir os dois primeiros romances de Dalcídio, apesar de publicados na década de 1940, entre as prosas de 1930, como "a linguagem [entre a poeticidade e a referencialidade], o retrato do herói [normalmente decadente] e as possibilidades de leitura desse herói, bem como o distanciamento do naturalismo [...]".

Concordamos com as ideias da intelectual. Há muito de arbitrário no que é, e pode ser, considerado um romance de 1930; na base temático-linguística, Chove nos campos de Cachoeira apresenta uma fatura tão somente vista nos grandes romancistas do período, levando-se em conta, a partir do distanciamento crítico de agora sobre a época, que "o resíduo literário nem sempre foi dos melhores” (LUCAS, 1976, p. 77) nas composições literárias de então.

Inseridos em uma grave polarização política, amiúde estudada, por exemplo, por Luís Bueno (2015) em Uma história do romance de 3o, os autores deveriam expressar o seu posicionamento ideológico não apenas em textos críticos, mas também em suas narrativas. Grosso modo, os escritores de esquerda eram compelidos a escrever prosas fincadas no chão social, enquanto os de direita normalmente compunham livros psicológicos, em que as tensões socio-históricas tendiam a desaparecer.

Dessa equação, felizmente, alguns escritores não participaram total ou parcialmente, combinando dialeticamente tensões ontológicas e sociais, o que

ORCID: http://orcid.org/0000-0002-4786-0716. E-mail: pedro.sonata@gmail.com

2 Além de Chove nos campos de Cachoeira, a Pará.grafo editora relançou, nos últimos dois anos, os seguintes romances do "Ciclo do Extremo-Norte" - composto, no total, de 11 obras - de Dalcídio Jurandir: Os habitantes, Três casas e um rio e Chão dos lobos. 
Flora Süssekind (1984, p. 198) denomina "literatura-contra" ou "literatura-lâmina". No âmbito dos prosadores da literatura-contra, temos: Jorge de Lima, Graciliano Ramos, Dyonélio Machado, Lúcio Cardoso, José Lins do Rego, Cyro dos Anjos, o nosso Dalcídio Jurandir, entre poucos outros.

Chove nos campos de Cachoeira nos dá a dimensão dos motivos que norteiam a nossa percepção de que Dalcídio Jurandir deve fazer parte dessa seleta lista.

A principal dessas razões talvez seja a desunião entre forma literária esperada e a visão política desse autor. Filiado ao Partido Comunista Brasileiro, sendo nele bastante atuante, aguardava-se dele um romance social, denunciador explícito das mazelas sofridas pela população da vila Cachoeira. Não nos deparamos com isso, no entanto. $\mathrm{O}$ romance movimenta-se entre o mergulho na psique das personagens, a crônica de costumes e o subtexto social, complexamente integrados.

Os primeiros dois capítulos do livro são de severa introspecção. No inicial, a perspectiva recai sobre Alfredo, filho de Major Alberto com a negra D. Amélia. O menino caminha pelos campos pensando na sua inadequação ao local. Nem branco nem negro, ele se posiciona em um entrelugar social e identitário, causador de violentos conflitos internos. Alfredo é o catalizador de um porvir não tão desolador - ambicionando estudar em Belém quanto das outras personagens, especialmente do seu meio-irmão Eutanázio.

Focalizador do capítulo segundo, Eutanázio vive sob o signo da tragédia, da inquietação e principalmente de uma melancolia atroz, não permitindo a ele vislumbrar o futuro. Mesmo antes de contrair uma grave doença sexual, ele já se sentia introduzido num intenso desamparo:

E Eutanázio pensava que doença do mundo ele tinha era na alma. Vinha sofrendo desde menino. Desde menino? Quem sabe se sua mãe não o botou no mundo como se bota um excremento? Sim, um excremento (JURANDIR, 2019, p. 31).

Nessa toada o longo capítulo continua. A personagem imputa severa culpa a si e aos outros, aviltando a todos, dando um sentido de duração à narrativa plasmada mediante o monólogo interior. A despeito da sua ruína, tanto existencial quanto econômica, ele supre as necessidades mais básicas da família de Irene, por quem ele é doentiamente apaixonado, fantasiando, reiteradamente, a própria morte da amada. Como Marlí Tereza Furtado (2015, p. 195) diz, essa personagem cumpre

um ritual diário de humilhação, num vaivém entre chalé do pai e o de seu Cristóvão [pai de Irene] e, instigantemente, como um flâneur, percorre as ruas de uma Cachoeira pobre, decaída, sem perspectivas.

Esse vigor da figuração do interior em direção ao exterior - o olhar do eu que vê a pobreza, por exemplo - perde um pouco de força nos capítulos subsequentes quando o enfoque da narrativa dá conta de mais personagens ou quando temos uma pausa na narração durante os diálogos. No primeiro caso, a expressividade psicológica dos outros seres-de-papel não se equivale à potência daquelas engendradas em Alfredo e Eutanázio, gerando uma pulverização de sofrimentos, que interessa à uma análise macro da narrativa por meio de uma noção de um sentimento geral de abandono. Com a germinação de diversas visadas no texto e do deslocamento espacial da narrativa, constrói-se, também, através das conversas entre as personagens, o modus vivendi dos seres da vila.

Contudo, se essa espécie de crônica de costume desvia a narrativa da sua tonalidade altamente introspectiva, ela edifica o seu subtexto social a partir do núcleo secundário de personagens. Conhecemos, por exemplo, nesse olhar panorâmico sobre a vila, o rico Dr. Campos. Juiz substituto do povoado, ele considera que a miséria do homem está vinculada à falta de crença em Deus. Em certo momento, ele é interpelado por Eutanázio:

\footnotetext{
- E a miséria do homem sem dinheiro?

— Ih! Estás ficando materialista, Eutanázio? Tu, um poeta! Um sensível?
} 
- Mas, pergunto, e a miséria do homem sem um tostão no bolso? Duma Felícia? (JURANDIR, 2019, p. 151).

Tais falas de Dr. Campos adquirem uma inflexão altamente insensível diante da paisagem de grave desolação humana com que ele inescapavelmente topa.

Outra evidência da figuração das tensões sociais está ligada, igualmente, no que acarreta o desnível entre riqueza e pobreza, dessa vez atado aos sonhos de Alfredo, que gostaria de se desligar da rotina e dos seres enfadonhos com quem convivia. O seu principal anseio, a fim de realizar a vontade de sair daquele meio medíocre, é estudar em Belém. Todavia, essa aspiração é reiteradamente tolhida pela falta de dinheiro. Antiteticamente, Tales de Mileto, garoto de família abastada, poderia educar-se onde Alfredo gostaria:

Tales tem um olhar, um silêncio e um jeito de quem tem certeza de que em Cachoeira só ele pode ir estudar em Belém. Isso é que dana Alfredo. Tales pensa que não é só porque tem dinheiro mas porque é o único que tem inteligência para estudar em Belém (JURANDIR, 2019, p. 277).

Levando-se em conta, igualmente, outros excertos da narrativa, apesar da modulação mesquinha com que Alfredo refere-se a Tales, através do narrador há uma noção de cobiça nessa personagem central, em tornar-se o outro social, em ser ele aquele que daria as costas "aos meninos infelizes e indignos de Cachoeira" (JURANDIR, 2019, p. 277).

Se até esse ponto do romance os embates sociais são configurados sub-repticiamente, nos capítulos finais do romance, especialmente no XVIII, eles manifestam-se de modo um pouco mais patente. Nesse capítulo, relata-se a chegada do Dr. Casemiro Lustosa, o benfeitor que, possuindo todas as terras da vila - detendo poder até sobre o ir e vir das pessoas sobre os campos - iria levá-la à civilização. Entretanto, o narrador, sarcasticamente, coloca em xeque a índole caridosa do pretenso libertador, justamente ao enfatizar o altruísmo do Dr. Lustosa. Contudo, em certo trecho, a instância narrativa deixa escapar a perniciosidade nas intenções do recém-chegado, como vemos em nossos grifos:

Não havia dúvida, o sonho desse homem era de proteger os pobres, dar nome a Cachoeira. Merecia até que os pobres não acendessem mais o fogão para que Bem Comum crescesse e progredisse (JURANDIR, 2019, p. 339, grifo nosso).

Ainda que o discurso em tal trecho seja inflexionado com o propósito de denunciar a colonização do capitalista rico sobre os pobres da região, camuflada na ideia de civilização e desenvolvimento, ele é modulado via ironia, muito diferentemente do que havia sido composto por Pagú, parte de Jorge Amado e outros escritores de esquerda.

Desse modo, e também pelo enorme grau de introspecção da narrativa, especialmente nas perspectivas de Eutanázio e Alfredo, esse romance não poderia ser visto como um documento, o que era uma perspectiva valorativa comum dedicada ao romance de 1930 (FURTADO, 2019, p. 63). Ao mesmo tempo, a prosa não deixa de trazer à tona conflitos histórico-sociais, o que os escritores de direita deploravam. Assim, de acordo com essas reflexões, Chove nos campos de Cachoeira destaca-se entre os romances-contra dos autores apontados no começo de nosso texto, que imbricam complexamente tensões sociais e ontológicas. Romance que agora pode ser lido em uma edição bonita e acessível.

\section{Referências}

BUENO, Luís. Uma história do romance de 30. São Paulo: EDUSP/Campinas: Editora da Unicamp, 2015.

FURTADO, Marlí Tereza. Dalcídio Jurandir e o romance de 30 ou um autor de 30 publicado em 40. Teresa, São Paulo, n. 16, p. 191-204, jun. 2015. https://doi.org/10.11606/issn.24478997.teresa.2015.115425

FURTADO, Pedro Barbosa Rudge. Ideologia, documento, permanência e anti-modismo: os termos valorativos do romance de 30. Revista Odisseia, Natal, v. 4, n. 1, p. 55-74, abr. 2019. https://doi.org/10.21680/1983-2435.2019v4n1id16827

JURANDIR, Dalcídio. Chove nos Campos de Cachoeira. 8. ed. Bragança: Pará grafo Editora, 2019.

LUCAS, Fábio. O caráter social da literatura brasileira. 2. ed. São Paulo: Quirón, 1976. 
PANTOJA, Edilson. Por que Chove nos campos de Cachoeira sobrevive ao tempo? In: JURANDIR, Dalcídio. Chove nos Campos de Cachoeira. 8. ed. Bragança: Pará.grafo Editora, 2019. p. 9-19. https://doi.org/10.12957/palimpsesto.2018.38366

SÜSSEKIND, Flora. Tal Brasil, qual romance? Uma ideologia estética e sua história: o naturalismo. Rio de Janeiro: Achiamé, 1984.

Recebido em: 16/9/2019.

Aprovado em: 30/9/2019.

\#35534

SEÇÃO: RESENHAS

Endereço de correspondência:

Rodovia Araraquara-Jaú Km 1 - Machados Araraquara/SP - CEP 14800-901 